\title{
Electrospray surface-enhanced Raman spectroscopy (ES-SERS) for prob- ing surface chemical compositions of atmospherically relevant particles
}

Masao Gen and Chak K. Chan

Correspondence to: Chak K. Chan (chak.k.chan@cityu.edu.hk)

The copyright of individual parts of the supplement might differ from the CC BY 3.0 License. 

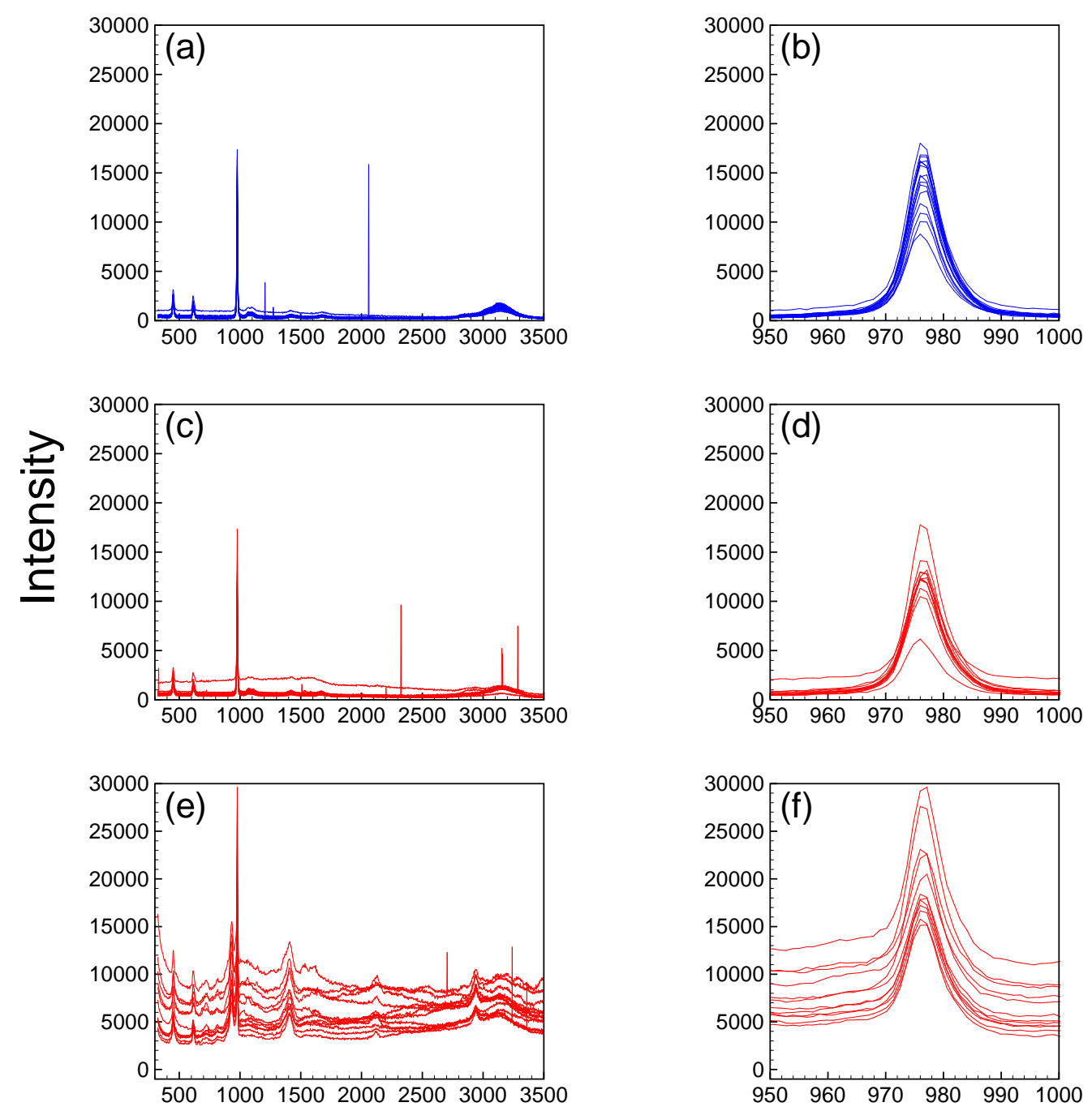

\section{Wavenumber $\left(\mathrm{cm}^{-1}\right)$}

Figure S1. (a) Normal and (c, e) enhanced spectra of AS particles which were used for quantification of $I_{\mathrm{SERS}} / I_{\mathrm{NR}}$. (b, d, f) Magnified views of spectra at $950-1000 \mathrm{~cm}^{-1}$ corresponding to $v\left(\mathrm{SO}_{4}{ }^{2-}\right)$. Note that in the presence of aggregated $\mathrm{Ag}$ nanoparticles, enhanced spectra (e) showed strong peaks of citrate at 2945, 1395, and $932 \mathrm{~cm}^{-1}$ corresponding to $v(\mathrm{C}-\mathrm{H}), v(\mathrm{COO})$ and $v(\mathrm{C}-\mathrm{COO})$, respectively. 


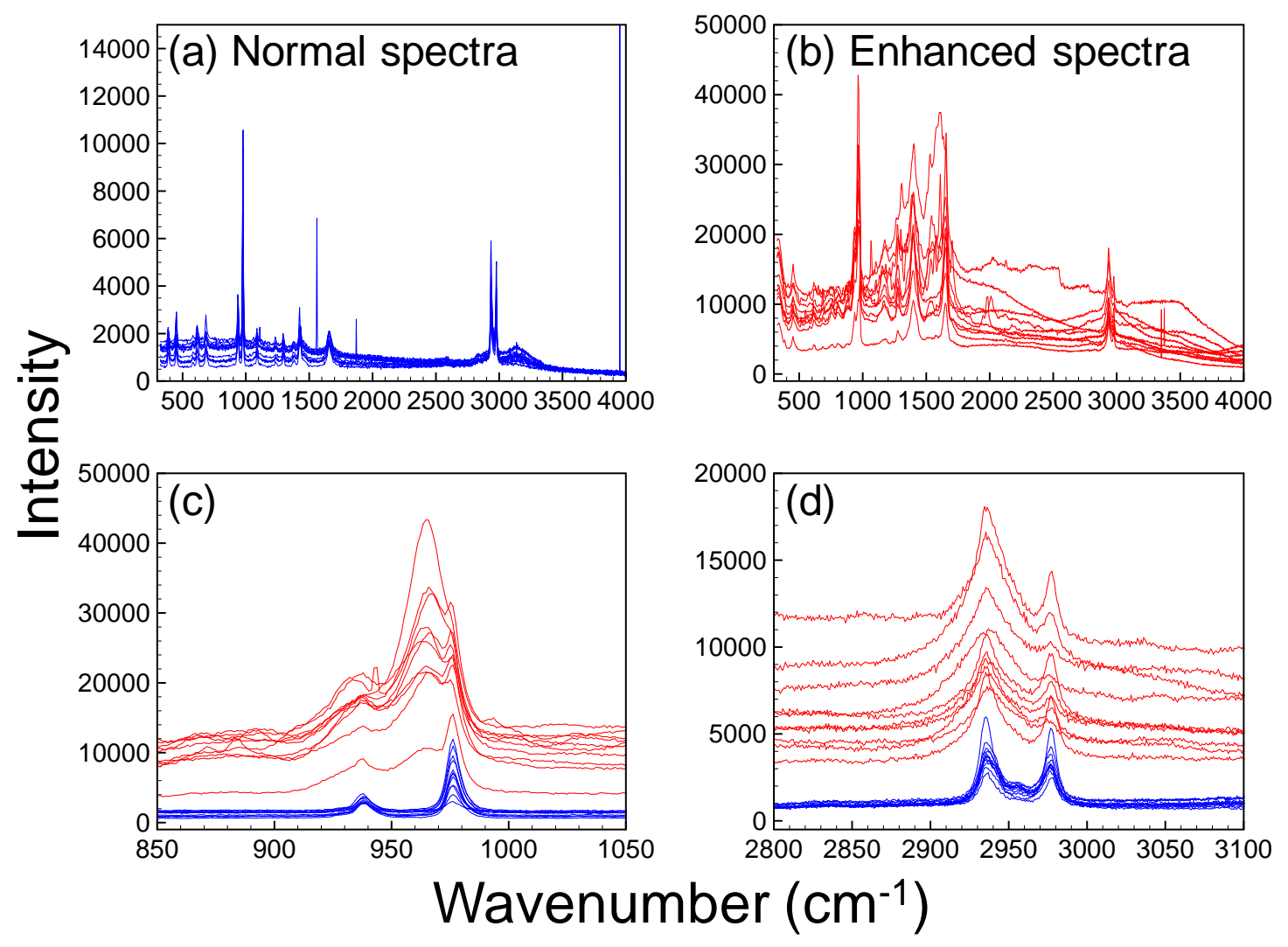

Figure S2. (a) Normal (blue) and (b) enhanced (red) spectra of AS/SA particles which were used for quantification of $I_{\mathrm{SERS}} / I_{\mathrm{NR}}$. (c, d) Magnified views of the corresponding spectra at 850-1050 and 2800-3100 $\mathrm{cm}^{-1}$ corresponding to $v\left(\mathrm{SO}_{4}{ }^{2-}\right)$ and $\delta(\mathrm{OH} \cdots \mathrm{O})$, and $v(\mathrm{C}-\mathrm{H})$, respectively. 

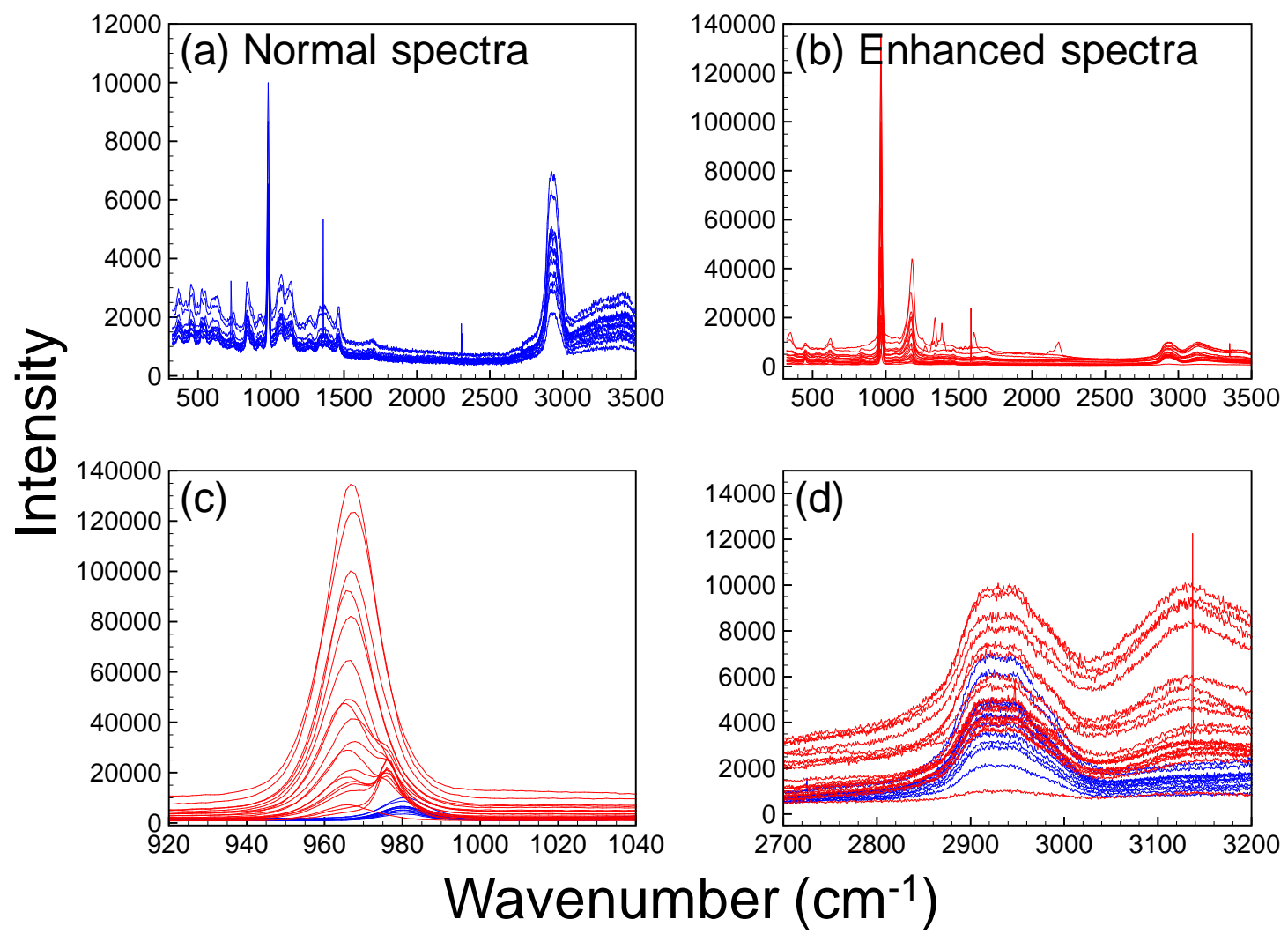

Figure S3. (a) Normal (blue) and (b) enhanced (red) spectra of AS/sucrose particles which were used for quantification of $I_{\mathrm{SERS}} / I_{\mathrm{NR}}$. (c, d) Magnified views of the corresponding spectra at $850-1050$ and $2800-3100 \mathrm{~cm}^{-1}$ corresponding to $v\left(\mathrm{SO}_{4}{ }^{2-}\right)$ and $v(\mathrm{C}-\mathrm{H})$, respectively. 


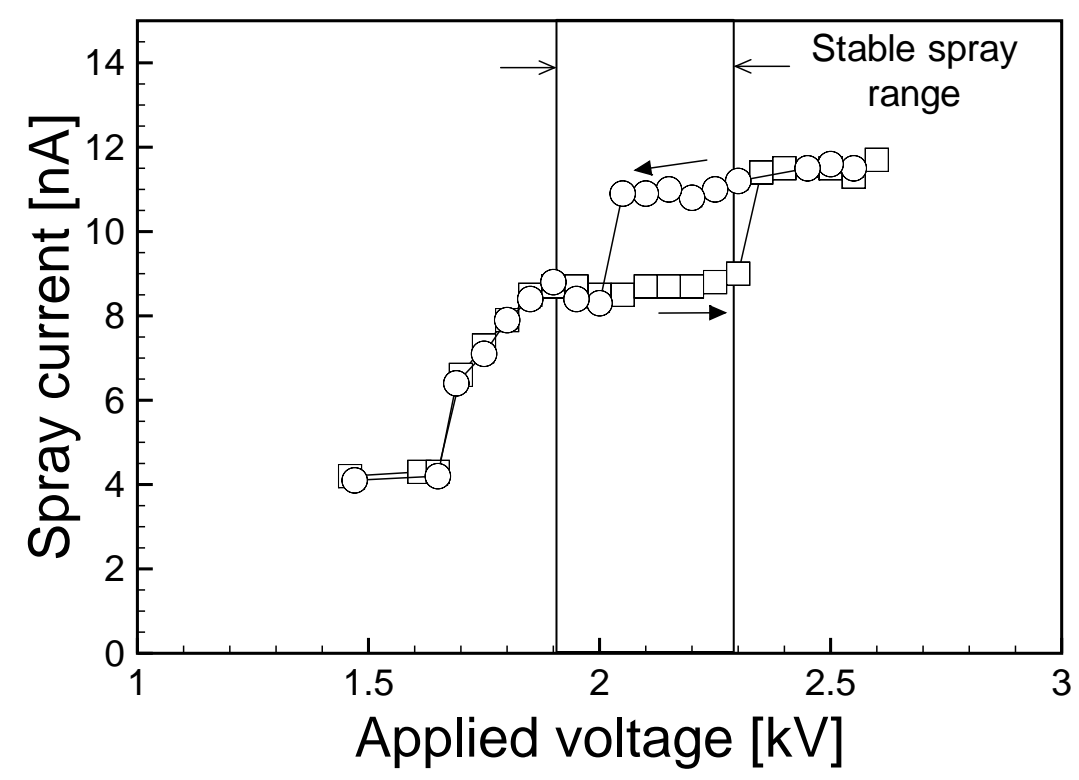

Figure S4. Plots of spray current versus applied voltage upon increasing and decreasing in the voltage.

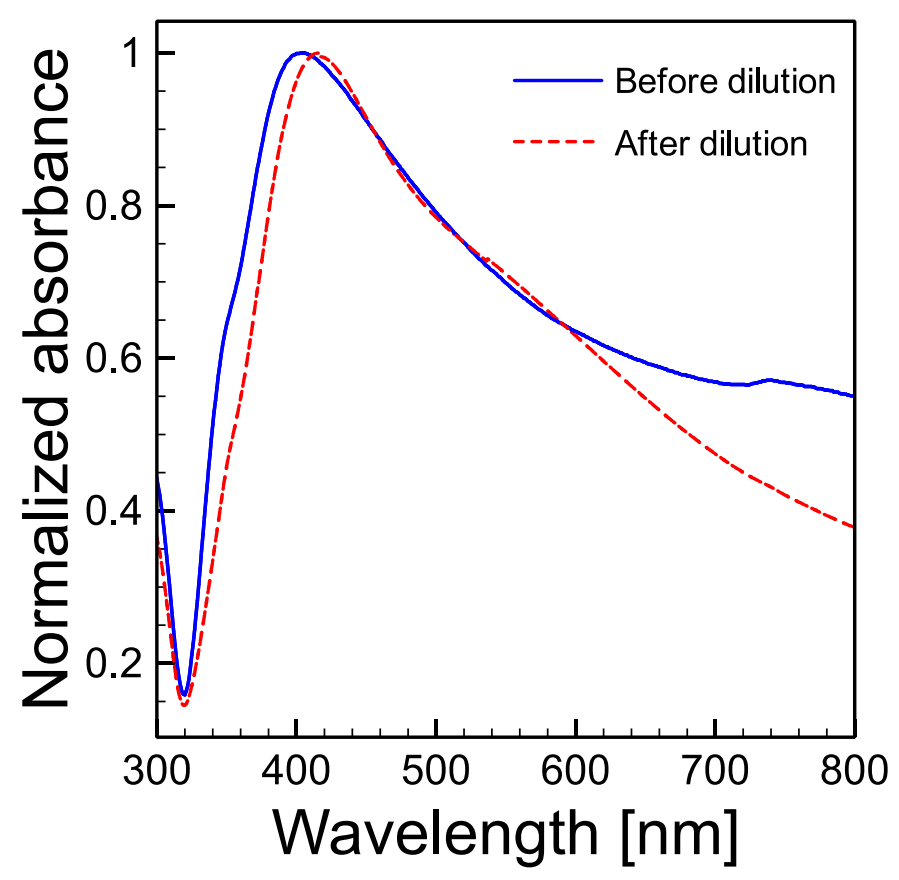

Figure S5. UV-vis spectra of Ag nanoparticle suspension before (blue solid line) and after (red dash line) dilution with ethanol at 1:1 volume ratio. 


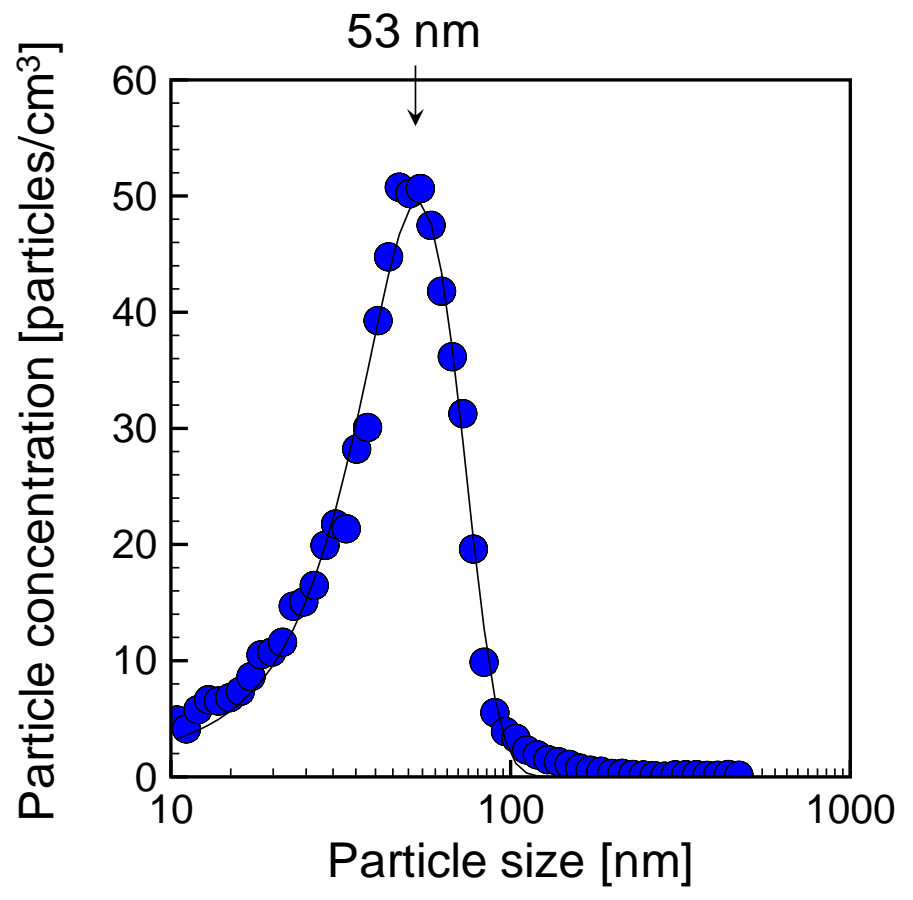

Figure S6. Electrically mobility size distribution of Ag nanoparticle aerosols in the gas phase measured by DMA + CPC. The solid line was fitted to normal distribution.
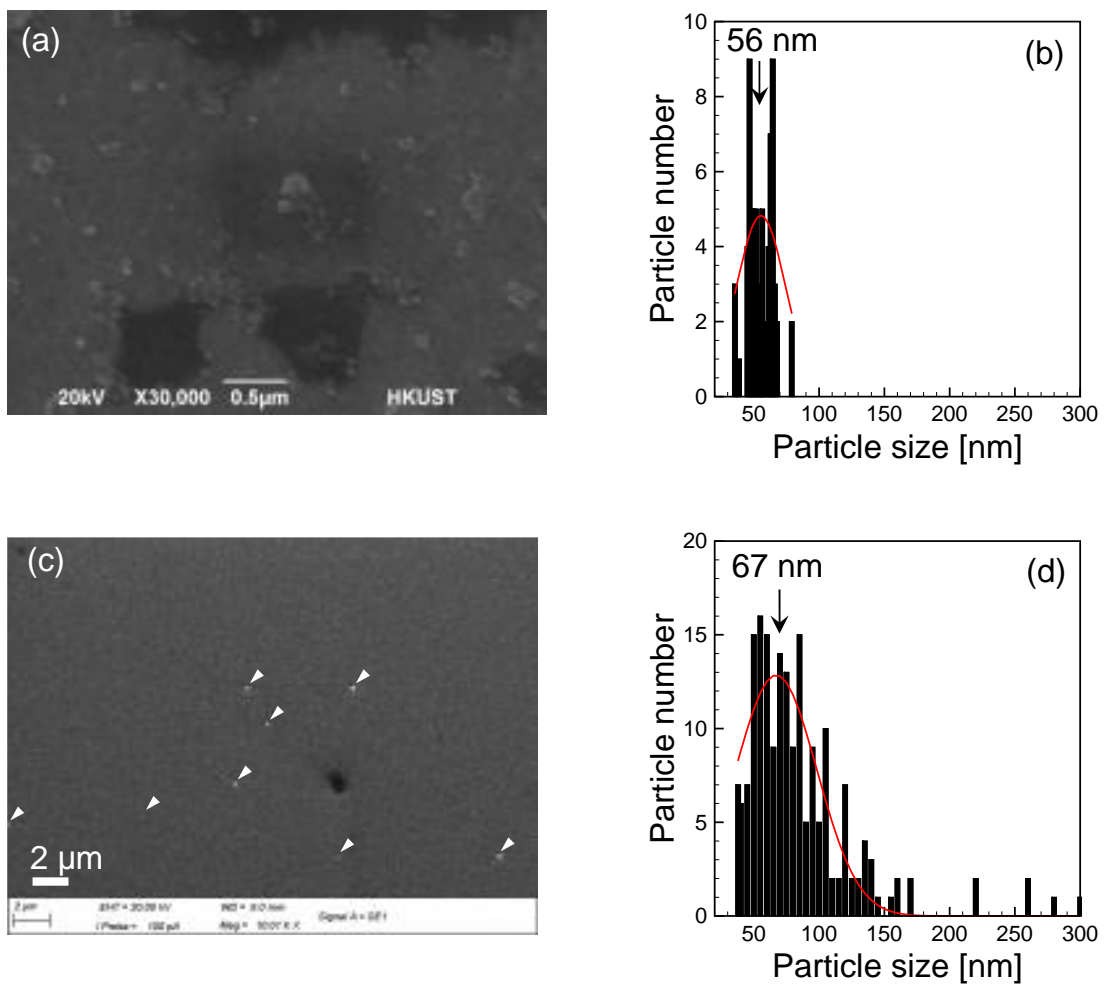

Figure S7. (a, c) SEM images of and (b, d) size distributions of Ag nanoparticles after naturally dried suspension and deposited (electrosprayed) on the substrate, respectively. Inset images shows typical SEM images. 71 and 208 particles were totally counted to obtain the size distributions for (b) and (d), respectively. The solid lines were fitted to normal distribution. 